\title{
ANALISIS PENJUALAN BAJU SERAGAM SEKOLAH DI KONVEKSI HANIFAH COLLECTION
}

\author{
Ahmad Fazarudin, Ahmad Nalhadi, Gerry Anugrah Dwiputra \\ Program Studi Teknik Industri, Fakultas Teknik, Universitas Serang Raya \\ Email: fazarudinahmad8@gmail.com; irqi02@gmail.com; gerry.adp@gmail.com
}

\begin{abstract}
Abstrak - Koleksi Hanifah merupakan perusahaan yang bergerak dalam bidang konveksi pakaian seragam sekolah. Jumlah permintaan setiap bulan yang berfluktuatif membuat permasalahan tersendiri dalam menentukan jumlah produksi. Penelitian ini bertujuan mencari metode yang sesuai dengan pola data yang sebagai dasar penentuan jumlah produksi di periode berikutnya. Metode yang digunakan dalam penelitian ini adalah metode peramalan Moving Average, Exponential Smoothing dan Triple Exponential Smoothing dengan parameter tingkat kesalahan dari masingmasing metode menggunakan menggunakan MAD, MSE dan MAPE. Dari hasil penelitian ini ada metode moving average dengan metode yang paling tepat dalam menentukan peramalan permintaan pada periode berikutnya dengan nilai nilai MAD sebesar 172.22, MSE sebesar 46624.34 dan MAPE 46624.34.
\end{abstract}

Kata kunci: Exponential Smoothing; Moving Average; Triple Exponential Smoothing

\begin{abstract}
Hanifah Collection is a company engaged in the convection of school uniforms. The fluctuating number of requests each month creates its problems in determining the amount of production. This study aims to find a method that matches the data pattern as the basis for determining the amount of output in the next period. The technique used in this study is the forecasting method of Moving Average, Exponential Smoothing and Triple Exponential Smoothing with parameter level errors of each way using MAD, MSE, and MAPE. From the results of this study, there is a moving average method with the most appropriate method in determining demand forecasting in the next period with a value of MAD of 172.22, MSE of 46624.34 and MAPE 46624.34.
\end{abstract}

Keywords: Exponential Smoothing; Moving Average; Triple Exponential Smoothing

\section{PENDAHULUAN}

Sebuah perusahaan didirikan mempunyai tujuan untuk menghasilkan barang dan jasa yang menjadi kebutuhan konsumen dan sekaligus untuk mendapatkan keuntungan dari usaha tersebut. Selain untuk mendapatkan keuntungan juga bertujuan untuk membantu pemerintah dalam mengurangi angka pengangguran dengan membuka lapangan pekerjaan serta bertujuan untuk mempertahankan dan meningkatkan kelangsungan hidup perusahaan di masa yang akan datang. Untuk mewujudkan itu semua, pemimpin perusahaan harus menetapkan suatu kebijakan yang tepat dalam mengelola perusahaan .

Konveksi Hanifah Collection terletak di pinggiran Kota Serang. Bergerak dalam industri pembuatan baju seragam sekolah. Konveksi tersebut memproduksi baju seragam sekolah putih dan pramuka SD,SMP serta SMA. Konveksi Hanifah Collection dalam memproduksi berdasarkan pesanan atau supplier. Perusahaan harus mempunyai konsep pengembangan sehingga perusahaan dapat berkembang di masa mendatang.

Perusahaan memerlukan perencanaan produksi yang lebih baik untuk menjaga kepercayaan konsumen. Salah satu langkah yang dapat dilakukan dalam strategi penjualan adalah melakukan prediksi penjualan yang menjadi faktor pendukung bagi perusahaan untuk melakukan kegiatan-kegiatan menuju kearah perkembangan pada masa yang akan dating (Muqtadiroh, Syofiani, \& Ramadhani, 2015). Keputusan yang diambil seorang pemimpin akan mempengaruhi suatu perusahaan dimasa yang akan datang. Pimpinan perusahaan harus mampu memprediksi permintaan produk di masa mendatang sehingga mampu memenuhi kebutuhan konsumen. Dalam membuat keputusan, pimpinan bersama pihak manajerial mampu membuat estimasi perkiraan kebutuhan di masa mendatang sehingga estimasi tersebut tidak terlalu jauh dari 
permintaan aktual di masa mendatang. Kegiatan untuk mengetahui atau memperkirakan apa yang akan terjadi pada masa yang akan datang disebut dengan peramalan (forecasting) (Wibowo, 2010)

Peramalan

merupakan proses perencanaan kebutuhan di periode masa datang dengan mempertimbangkan sumber daya yang dimiliki dalam rangka memenuhi barang atau jasa (Nasution, 2006; Render \& Heizer, 2005).Peramalan dilakukan bertujuan agar mengetahui perkiraan jumlah penjualan yang akan datang dan jumlah kesalahan ramalan, sehingga untuk memenuhi kebutuhan konsumen, manajemen perusahaan membuat peramalan penjualan produk

Pemilihan metode peramalan mempertimbangkan model data historis yang ada dalam suatu perusahaan. Model peramalan ratarata bergerak (moving average), atau pemulusan eksponensial (exponential smoothing) dapat digunakan untuk pola data yang tidak membentuk kecenderungan (Supriyadi \& Riskiyadi, 2016). Model peramalan ini telah banyak diimplementasikan dalam menunjang proyeksi di masa mendatang.(Djie, 2013; Jana, 2016; Marsetiani, 2014; Sanny \& Sarjono, 2013).

Penelitian ini bertujuan memperkirakan kebutuhan produksi di periode berikutnya dengan menggunakan metode moving average dan exponential smoothing. Hasil pemilihan peramalan dapat dijadikan referensi bagi perusahaan dalam memperkirakan kebutuhan produksi di masa mendatang.

\section{METODE PENELITIAN}

Penelitian dilakukan di konveksi hanifah collection dengan menggunakan data penjualan produk selama Juni 2015 sampai mei 2017. Pengolahan data dilakukan dengan menggunakan metode single moving averages, exponential smoothing dan triple exponential smoothing winter's. Dari ketiga metode tersebut dipilih berdasarkan nilai Mean Absolute Deviation (MAD), Mean Square Error (MSE) dan Mean Absolute Percentage of Error (MAPE) terkecil.

Metode moving average digunakan dalam memprediksi permintaan dengan cara melakukan perhitungan nilai rata-rata dari nilai permintaan sesungguhnya dari sejumlah periode sebelumnya. Setiap prediksi baru ditetapkan pada periode yang lama dan diganti dengan permintaan dari periode yang baru, sehingga data pada perhitungan berpindah sepanjang waktu sesuai dengan metode ini. Metode simple moving average digunakan untuk data yang bersifat tidak stabil, tidak memiliki trend dan tidak menggunakan pembobotan pada data.
$F_{t+1}=\frac{1}{n} \sum_{i=t-n+1}^{t} A_{i}$

$F_{t+1} \quad$ : Prediksi untuk periode $\mathrm{t}+1$

$\mathrm{N}$ : Jumlah periode yang digunakan untuk menghitung moving average

$A_{i} \quad$ : Nilai sesungguhnya pda periode $i$

Metode exponential smoothing merupakan metode peramalan yang menunjukkan pembobotan menurun secara eksponensial terhadap nilai pengamatan yang lebih lama. Terdapat satu atau lebih parameter penulisan yang ditentukan secara eksplisit, dan hasil pilihan ini menentukan bobot yang dikenakan pada nilai observasi (Makridakis, Wheelwright, \& McGee, 1999).

$\hat{Y}_{t+1}=\alpha Y_{t}+(1-\alpha) \hat{Y}_{t}$

Keterangan

$\hat{\mathrm{Y}}_{\mathrm{t}+1} \quad$ : Nilai ramalan untuk periode selanjutnya

a : Konstanta pemulusan

$Y_{t} \quad$ : Data baru nilai $Y$ yang sebenarnya pada periode t.

$\hat{\mathrm{Y}}_{\mathrm{t}} \quad$ : Nilai pemulusan yang lama atau ratarata pemulusan hingga periode $\mathrm{t}-1$

Metode triple exponential smoothing winter's merupakan metode yang dapat menangani faktor musiman dan trend secara langsung. Keuntungan dari metode triple exponential smoothing winter's adalah memiliki kemampuan yang sangat baik dalam meramalkan data yang memiliki pola trend dan musiman (Makridakis et al., 1999).

a. Estimasi Level

$\hat{L}_{t}=\alpha \frac{Y_{t}}{S_{t-1}}+(1-\alpha)\left(L_{t-1}+T_{t-1}\right)$

b. Estimasi Trend

$\widehat{T}_{t}=\beta\left(L_{t}-L_{t-1}\right)+(1-\beta) T_{t-1}$

C. Estimasi Musiman

$\hat{S}_{t}=\gamma \frac{Y_{t}}{L_{t}}+(1-\gamma) S_{t-s}$

d. Peramalan $p$ periode mendatang

$\widehat{Y}_{t-p}=\left(L_{t}+p T_{t}\right) S_{t-s+p}$

dengan

$\hat{L}_{t}$ : Estimasi level pada akhir periode $t$

$\alpha$ : Konstanta smoothing untuk estimasi level $(0<\alpha<1)$

$\widehat{T}_{t}$ : Estimasi trend pada akhir periode $\mathrm{t}$

$\beta$ : Konstanta smoothing untuk estimasi trend $(0<\beta<1)$

$\hat{S}_{t}$ : Estimasi musiman pada akhir periode $t$ 
$\gamma:$ Konstanta smoothing untuk estimasi musiman $(0<\gamma<1)$

$\hat{Y}_{t}$ : Banyaknya penjualan pada periode $t$

$s:$ Periode musiman

Langkah selanjutnya adalah menentukan nilai Mean Absolute Deviation (MAD), Mean Square Error (MSE) dan Mean Absolute Percentage of Error (MAPE). MAD merupakan rata-rata kesalahan mutlak selama periode tertentu tanpa memperhatikan apakah hasil peramalan lebih besar atau lebih kecil dibandingkan kenyataannya. Ukuran pertama kesalahan peramalan keseluruhan untuk sebuah model adalah MAD. Nilai ini dihitung dengan mengambil jumlah nilai absolut dari tiap kesalahan peramalan dibagi dengan jumlah periode data $(\mathrm{n})$.

$$
M A D=\frac{\sum\left|\mathrm{f}_{\mathrm{t}}-\hat{\mathrm{f}}_{\mathrm{t}}\right|}{\mathrm{m}}
$$

$$
\begin{array}{ll}
\mathrm{f}_{\mathrm{t}} & \text { : Data actual pada periode } \mathrm{t} \\
\hat{\mathrm{f}}_{\mathrm{t}} & \text { : Nilai peramalan periode } \mathrm{t} \\
\mathrm{m} & \text { : Banyaknya data ramalan }
\end{array}
$$

Mean Square Error (MSE) merupakan rataan selisih kuadrat antara nilai yang 19 diramalkan dan yang diamati. MSE merupakan metode alternatif dalam suatu metode peramalan. Pendekatan ini penting karena teknik ini menghasilkan kesalahan yang moderat lebih disukai oleh suatu peramalan yang menghasilkan kesalahan yang sangat besar. MSE dihitung dengan menjumlahkan kuadrat semua kesalahan peramalan pada setiap periode dan membaginya dengan jumlah periode peramalan.

$$
M S E=\frac{\sum\left|\mathrm{f}_{\mathrm{f}}-\hat{\mathrm{f}}_{\mathrm{t}}\right|^{2}}{\mathrm{~m}}
$$

\footnotetext{
$\mathrm{f}_{\mathrm{t}} \quad$ : Data actual pada periode $t$

$\hat{\mathrm{f}}_{\mathrm{t}} \quad$ : Nilai peramalan periode $\mathrm{t}$

$\mathrm{m}$ : Banyaknya data ramalan
}

Mean Absolute Percentage of Error (MAPE) merupakan ukuran kesalahan relatif dan menyatakan persentase kesalahan hasil peramalan terhadap permintaan aktual selama periode tertentu yang akan memberikan informasi persentase kesalahan terlalu tinggi atau terlalu rendah. Masalah yang terjadi dengan MAD dan MSE adalah bahwa nilainya tergantung pada besarnya unsur yang diramal. Jika unsur tersebut dihitung dalam satuan ribuan, maka nilai MAD dan MSE menjadi sangat besar. Untuk menghindari masalah ini, dapat menggunakan MAPE. MAPE dihitung sebagai rataan diferensiasi absolut antara nilai yang diramal dan aktual, dinyatakan sebagai persentase nilai aktual.

$M A P E=\frac{\sum\left|\mathrm{f}_{\mathrm{t}}-\hat{\mathrm{f}}_{\mathrm{t}}\right| / \mathrm{f}_{\mathrm{t}} \times 100 \%}{m}$

$f_{t} \quad$ : Data actual pada periode $t$

$\hat{\mathrm{f}}_{\mathrm{t}} \quad$ : Nilai peramalan periode $t$

$\mathrm{m}$ : Banyaknya data ramalan

\section{HASIL DAN PEMBAHASAN}

Data yang digunakan dalam melakukan forecasting adalah menggunakan data penjualan selama Juni 2015 sampai mei 2017 (Tabel 1). Langkah selanjutnya adalah menggunakan ketiga metode peramalan untuk mendapatkan nilai Mean Absolute Deviation (MAD), Mean Square Error (MSE) dan Mean Absolute Percentage of Error (MAPE)..

Pengolahan data dalam penelitian ini menggunakan moving average 3 bulanan (Tabel 2), exponential dengan $\alpha=0.2$ (Tabel 3) dan triple exponentialsmoothing winter's (Tabel 4) Contoh perhitungan moving average 3 bulanan adalah sebagai berikut:

$\hat{f}_{t}=\frac{f_{t-1}+f_{t-2}+f_{t-3}}{m}$

$\hat{f}_{25}=\frac{f_{24}+f_{23}+f_{22}}{3}$

$\hat{f}_{13}=\frac{1230+1400+1520}{3}$

$\hat{f}_{13}=1383.3 \approx 1384$

Untuk menghitung peramalan dengan menggunakan metode Exponential Smoothing peneliti mengasumsikan $\alpha=0.2$ dan hasil pengolahan data untuk metode ini adalah sebagai berikut:

$\hat{f} \mathrm{t}=\left(\alpha \times f_{t-1}\right)+\left((1-\alpha) \times \hat{f}_{t-1}\right)$

$\hat{f} \mathrm{t}=\left(\alpha \times f_{t-1}\right)+\left((1-\alpha) \times \hat{f}_{t-1}\right)$

$\hat{f}_{25}=(0.2 \times 1520)+((1-0.2) \times 1300.10)$

$\hat{f}_{13}=(304)+(0.8 \times 1300.10)$

$\hat{f}_{13}=(304)+(1040.08)$

$\hat{f}_{13}=1344.08 \approx 1345$

Langkah selanjutnya adalah menentukan nilai Mean Absolute Deviation (MAD), Mean Square Error (MSE) dan Mean Absolute Percentage of Error (MAPE). Perhitungan ini memerlukan data Absolute Error, nilai error pangkat dua $\left(\mathrm{e}^{2}\right)$ dan nilai \% error $(\mathrm{e} \%)$. 
Tabel 1. Data penjualan periode 2015-2017

\begin{tabular}{cccccc}
\hline Tahun & Bulan & Penjualan & Tahun & Bulan & Penjualan \\
\hline 2015 & Juni & 1150 & 2016 & Juni & 1740 \\
2015 & Juli & 1100 & 2016 & Juli & 1650 \\
2015 & Agustus & 1000 & 2016 & Agustus & 1540 \\
2015 & September & 900 & 2016 & September & 1350 \\
2015 & Oktober & 850 & 2016 & Oktober & 1280 \\
2015 & November & 750 & 2016 & November & 1130 \\
2015 & Desember & 750 & 2016 & Desember & 1270 \\
2016 & Januari & 800 & 2017 & Januari & 1230 \\
2016 & Februari & 1200 & 2017 & Februari & 1315 \\
2016 & Maret & 1100 & 2017 & Maret & 1230 \\
2016 & April & 1250 & 2017 & April & 1400 \\
2016 & Mei & 1300 & 2017 & Mei & 1520 \\
\hline
\end{tabular}

Tabel 2. Peramalan dengan moving average 3 bulanan

\begin{tabular}{lcccccc}
\hline \multicolumn{1}{c}{ Bulan } & Penjualan $\mathrm{f}_{\mathrm{t}}$ & MA $(3) \hat{f}_{\mathrm{t}}$ & Eror & $\mid$ Eror $\mid$ & $\mathrm{e}^{2}$ & $\%$ Error \\
\hline Juni & 1150 & & & & & \\
Juli & 1100 & & & & & \\
Agustus & 1000 & & & & & \\
September & 900 & 1083.33 & -183.33 & 183.33 & 33611.11 & 20.37 \\
Oktober & 850 & 1000.00 & -150.00 & 150.00 & 22500.00 & 17.65 \\
November & 750 & 916.67 & -166.67 & 166.67 & 27777.78 & 22.22 \\
Desember & 750 & 833.33 & -83.33 & 83.33 & 6944.44 & 11.11 \\
Januari & 800 & 783.33 & 16.67 & 16.67 & 277.78 & 2.08 \\
Februari & 1200 & 766.67 & 433.33 & 433.33 & 187777.78 & 36.11 \\
Maret & 1100 & 916.67 & 183.33 & 183.33 & 33611.11 & 16.67 \\
April & 1250 & 1033.33 & 216.67 & 216.67 & 46944.44 & 17.33 \\
Mei & 1300 & 1183.33 & 116.67 & 116.67 & 13611.11 & 8.97 \\
Juni & 1740 & 1216.67 & 523.33 & 523.33 & 273877.78 & 30.08 \\
Juli & 1650 & 1430.00 & 220.00 & 220.00 & 48400.00 & 13.33 \\
Agustus & 1540 & 1563.33 & -23.33 & 23.33 & 544.44 & 1.52 \\
September & 1350 & 1643.33 & -293.33 & 293.33 & 86044.44 & 21.73 \\
Oktober & 1280 & 1513.33 & -233.33 & 233.33 & 54444.44 & 18.23 \\
November & 1130 & 1390.00 & -260.00 & 260.00 & 67600.00 & 23.01 \\
Desember & 1270 & 1253.33 & 16.67 & 16.67 & 277.78 & 1.31 \\
Januari & 1230 & 1226.67 & 3.33 & 3.33 & 11.11 & 0.27 \\
Februari & 1315 & 1210.00 & 105.00 & 105.00 & 11025.00 & 7.98 \\
Maret & 1230 & 1271.67 & -41.67 & 41.67 & 1736.11 & 3.39 \\
April & 1400 & 1258.33 & 141.67 & 141.67 & 20069.44 & 10.12 \\
Mei & 1520 & 1315.00 & 205.00 & 205.00 & 42025.00 & 13.49 \\
\hline JUMLAH & 28805 & 24808.33 & 746.667 & 3616.67 & 979111.11 & 296.9726 \\
\hline & & & & & & \\
\hline
\end{tabular}


Tabel 3. Peramalan exponential dengan $\alpha=0.2$

\begin{tabular}{lcccccc}
\hline \multicolumn{1}{c}{ Bulan } & Penjualan $\mathrm{f}_{\mathrm{t}}$ & $\hat{f}_{\mathrm{t}}$ & Eror & $\mid$ Eror $\mid$ & $\mathrm{e}^{2}$ & \% Error \\
\hline Juni & 1150 & & & & & \\
Juli & 1100 & 1150 & -50.00 & 50.00 & 2500.00 & 4.55 \\
Agustus & 1000 & 1140.00 & -140.00 & 140.00 & 19600.00 & 14.00 \\
September & 900 & 1112.00 & -212.00 & 212.00 & 44944.00 & 23.56 \\
Oktober & 850 & 1069.60 & -219.60 & 219.60 & 48224.16 & 25.84 \\
November & 750 & 1025.68 & -275.68 & 275.68 & 75999.46 & 36.76 \\
Desember & 750 & 970.54 & -220.54 & 220.54 & 48639.66 & 29.41 \\
Januari & 800 & 926.44 & -126.44 & 126.44 & 15985.86 & 15.80 \\
Februari & 1200 & 901.15 & 298.85 & 298.85 & 89312.42 & 24.90 \\
Maret & 1100 & 960.92 & 139.08 & 139.08 & 19343.66 & 12.64 \\
April & 1250 & 988.73 & 261.27 & 261.27 & 68259.49 & 20.90 \\
Mei & 1300 & 1040.99 & 259.01 & 259.01 & 67087.29 & 19.92 \\
Juni & 1740 & 1092.79 & 647.21 & 647.21 & 418880.41 & 37.20 \\
Juli & 1650 & 1222.23 & 427.77 & 427.77 & 182985.27 & 25.93 \\
Agustus & 1540 & 1307.79 & 232.21 & 232.21 & 53923.44 & 15.08 \\
September & 1350 & 1354.23 & -4.23 & 4.23 & 17.88 & 0.31 \\
Oktober & 1280 & 1353.38 & -73.38 & 73.38 & 5385.05 & 5.73 \\
November & 1130 & 1338.71 & -208.71 & 208.71 & 43558.33 & 18.47 \\
Desember & 1270 & 1296.97 & -26.97 & 26.97 & 727.11 & 2.12 \\
Januari & 1230 & 1291.57 & -61.57 & 61.57 & 3791.12 & 5.01 \\
Februari & 1315 & 1279.26 & 35.74 & 35.74 & 1277.52 & 2.72 \\
Maret & 1230 & 1286.41 & -56.41 & 56.41 & 3181.65 & 4.59 \\
April & 1400 & 1275.12 & 124.88 & 124.88 & 15593.79 & 8.92 \\
Mei & 1520 & 1300.10 & 219.90 & 219.90 & 48356.05 & 14.47 \\
\hline JUMLAH & 28805 & 26684.60036 & 970.40 & 4321.44 & 1277573.62 & 368.81 \\
\hline & & & & & & \\
\hline
\end{tabular}

Tabel 4 Peramalan triple exponential smoothing winter's

\begin{tabular}{lcccccr}
\hline \multicolumn{1}{c}{ Bulan } & Penjualan $\mathrm{f}_{\mathrm{t}}$ & $\hat{f}_{\mathrm{t}}$ & Error & $\mid$ Error $\mid$ & $\mathrm{e}^{2}$ & \% Error \\
\hline Juni & 1150 & 1655.321 & -505.321 & 505.3209 & 255349.2613 & 0.43941 \\
Juli & 1100 & 1524.408 & -424.408 & 424.408 & 180122.1316 & 0.385825 \\
Agustus & 1000 & 1336.577 & -336.577 & 336.5773 & 113284.2902 & 0.336577 \\
September & 900 & 1163.451 & -263.451 & 263.4507 & 69406.25177 & 0.292723 \\
Oktober & 850 & 924.8257 & -74.8257 & 74.8257 & 5598.884691 & 0.08803 \\
November & 750 & 676.1839 & 73.81611 & 73.81611 & 5448.818575 & 0.098421 \\
Desember & 750 & 347.051 & 402.949 & 402.949 & 162367.905 & 0.537265 \\
Januari & 800 & 35.91924 & 764.0808 & 764.0808 & 583819.4154 & 0.955101 \\
Februari & 1200 & 501.2541 & 698.7459 & 698.7459 & 488245.7819 & 0.582288 \\
Maret & 1100 & 1050.081 & 49.91914 & 49.91914 & 2491.920175 & 0.045381 \\
April & 1250 & 1661.919 & -411.919 & 411.9188 & 169677.0989 & 0.329535 \\
Mei & 1300 & 2544.422 & -1244.42 & 1244.422 & 1548586.233 & 0.957248 \\
Juni & 1740 & 4729.01 & -2989.01 & 2989.01 & 8934183.387 & 1.717822 \\
\hline
\end{tabular}


Tabel 4. Peramalan triple exponential smoothing winter's (Lanjutan)

\begin{tabular}{ccccccc}
\hline Bulan & Penjualan $\mathrm{f}_{\mathrm{t}}$ & $\hat{f}_{\mathrm{t}}$ & Error & $\mid$ Error $\mid$ & $\mathrm{e}^{2}$ & $\%$ Error \\
\hline Juli & 1650 & 6698.779 & -5048.78 & 5048.779 & 25490172.66 & 3.059866 \\
Agustus & 1540 & 9074.384 & -7534.38 & 7534.384 & 56766934.85 & 4.892457 \\
September & 1350 & 12486.27 & -11136.3 & 11136.27 & 124016398.7 & 8.249085 \\
Oktober & 1280 & 17181.74 & -15901.7 & 15901.74 & 252865323.9 & 12.42323 \\
November & 1130 & 24417.74 & -23287.7 & 23287.74 & 542318796.4 & 20.60862 \\
Desember & 1270 & 39612.63 & -38342.6 & 38342.63 & 1470157605 & 30.19105 \\
Januari & 1230 & 238580.8 & -237351 & 237350.8 & 56335405449 & 192.9681 \\
Februari & 1315 & 20814.27 & -19499.3 & 19499.27 & 380221668.5 & 14.82834 \\
Maret & 1230 & 21963.45 & -20733.5 & 20733.45 & 429876021.9 & 16.85646 \\
April & 1400 & 37864.73 & -36464.7 & 36464.73 & 1329676745 & 26.04624 \\
Mei & 1520 & 1655.321 & -59838.8 & 59838.77 & 3580678630 & 39.36761 \\
\hline
\end{tabular}

Tabel 5. Nilai MAD, MSE dan MAPE

\begin{tabular}{llll}
\hline & MA & ES & TES \\
\hline MAD & 172.22 & 187.89 & 20140.75 \\
MSE & 46624.34 & 55546.68 & 2689166347 \\
MAPE & $14.14 \%$ & $16.4 \%$ & $15.67 \%$ \\
\hline
\end{tabular}

Dari hasil nilai Mean Absolute Deviation (MAD), Mean Square Error (MSE) dan Mean Absolute Percentage of Error (MAPE) (Tabel 5) terpilih moving average 3 bulanan dengan nilai 172,22 untuk MAD, 46624.34 untuk MSE dan $14.14 \%$ untuk nilai MAPE. Dengan menggunakan metode moving average 3 bulanan dapat dilakukan perkiraan penjualan Juni 2017 sebesar 1384 buah, bulan juli 2017 sebesar 1460 buah dan bulan agustus sebanyak 1520 buah.

\section{KESIMPULAN}

Berdasarkan hasil pengolahan data yang dilakukan, metode moving average 3 bulanan merupakan metode yang sesuai dengan pola data yang ada dibandingkan dengan metode exponential $\alpha=0.2$ dan triple exponential smoothing winter's dengan nilai MAS sebesar 172,22, MSE sebesar 46624.34 dan nilai MAPE $14.14 \%$. Berdasarkan metode moving average 3 bulanan dapat dilakukan perkiraan penjualan Juni 2017 sebesar 1384 buah, bulan juli 2017 sebesar 1460 buah dan bulan agustus sebanyak 1520 buah

\section{DAFTAR PUSTAKA}

Djie, I. S. J. (2013). Analisis Peramalan Penjualan dan Penggunaan Metode Linear Programming dan Decision Tree Guna Mengoptimalkan Keuntungan pada PT Primajaya Pantes Garment. The Winners, 14(2), 113-119.
Jana, P. (2016). Aplikasi Triple Exponential Smoothing Untuk Forecasting Jumlah Penduduk Miskin. Jurnal Derivat, 3(2), 7681.

Makridakis, S., Wheelwright, S. C., \& McGee, V. E. (1999). Metode dan aplikasi peramalan. Jakarta: Erlangga.

Marsetiani, M. (2014). Model Optimasi Penentuan Kombinasi Produk Menggunakan Metode Linear Programming pada Perusahaan Bidang Fashion. The Winners, 15(1), 1-7.

Muqtadiroh, F. A., Syofiani, A. R., \& Ramadhani, T. S. (2015). Analisis Peramalan Penjualan Semen Non-Curah (ZAK) PT Semen Indonesia (Persero) Tbk Pada Area Jawa Timur. In Seminar Nasional Teknologi Informasi dan Komunikasi (pp. 308-310).

Nasution, A. H. (2006). Manajemen industri. Yogyakarta: Penerbit Andi.

Render, B., \& Heizer, J. (2005). Manajemen Operasi. Jakarta: Salemba Empat.

Sanny, L., \& Sarjono, H. (2013). Peramalan Jumlah Siswa/l Sekolah Menengah Atas Swasta Menggunakan Enam Metode Forecasting. In Forum Ilmiah (Vol. 10, pp. 198-208).

Supriyadi, S., \& Riskiyadi, R. (2016). Penjadwalan Produksi IKS-Filler Pada Proses Ground Calcium Carbonate Menggunakan Metode MPS Di Perusahaan Kertas. Jurnal IImiah SINERGI, 20(2), 157164.

Wibowo, I. (2010). Analisis Peramalan Penjualan Rokok Golden Pada PT. Djitoe Indonesian Tobacco Coy Surakarta, Skripsi, Universitas Sebelas Maret. 